\section{The Many Faces of} Acquired Neurologic Mutism in Childhood

\author{
Marijke van Mourik, MA*', \\ Hugo R. van Dongen, $\mathrm{PhD}^{*}$, and \\ Coriene E. Catsman-Berrevoets, $\mathrm{MD}, \mathrm{PhD}^{*}$
}

Acquired neurologic mutism in childhood is a complex phenomenon occurring in various neurologic conditions with different etiologies. We illustrate its clinical heterogeneity as reflected in a wide range of concomitant behavioral features by presenting 4 children with acquired neurologic mutism. Neuropsychologic examinations revealed differential patterns of defective or preserved phonation, orofacial movements, communicative behavior, and linguistic functions. We propose that detailed neuropsychologic analysis contributes to descriptions of the evolution of the speech impairment beyond the mute phase and the long-term disability. A framework for the clinical evaluation of children is therefore presented. (c) 1996 by Elsevier Science Inc. All rights reserved.

van Mourik M, van Dongen HR, Catsman-Berrevoets CE. The many faces of acquired neurologic mutism in childhood. Pediatr Neurol 1996;15:352-357.

\section{Introduction}

Patients are diagnosed with neurologic mutism when an organic lesion can reasonably be held responsible for the absence of verbal output or when the mutism is associated with other deficits suggestive of dysfunction of the central nervous system (CNS) [1]. Acquired neurologic childhood mutism (ANCM) may be caused by damage in different brain regions in the context of diverse etiologies (Table 1, [2-21]). ANCM may therefore be associated with a wide range of neurologic and neuropsychologic deficits such as cranial nerve paresis, absence of phonation, disturbed simple and complex orofacial movements, absence of communicative urge, or loss of comprehension of spoken language.

Pediatric studies usually mention the presence of ANCM in case studies as a sign of a specific disease, but associated behavioral features have not been analyzed in detail. Therefore, the possible prognostic value of such features for recovery from mutism or for long term sequelae is not known. We wished to (a) illustrate the heterogeneity of the neuropsychologic disorders that contribute to the many faces of ANCM and (b) provide a framework for the clinical evaluation of mute children.

\section{Case Reports}

We describe 4 children with ANCM. Cases 1, 2, and 4 previously had normal psychomotor and language development. Case 3 had developmental motor problems, but normal speech, language, and scholastic ability. All children were examined identically and were videotaped on several occasions. Table 2 presents the characteristic neurobehavioral features in each patient to illustrate distinct clinical presentations of ANCM.

Case 1. In the acute phase, an 11-year-old boy sustained severe head injury. On his hospital admission, the Glasgow Coma Scale (GCS) was EIMIVI. CT scan disclosed hemorrhages in the left frontoparietal region and in the right insula. Epileptic seizures occurred frequently. EEG showed slow background activity with epileptic foci in the right temporoparieto-occipital and in the left frontal regions. In the next 3 weeks, he developed spastic quadriplegia. He could suck and swallow and could eat when fed. His eyes followed moving objects and persons approaching him. He made no attempts to speak although he "seemed to give promise of speech." He could not be stimulated to communicate in any other way. He did not show facial emotional expression and did not phonate in emotional context. Four months after the accident, in a videotaped session, he was still akinetic and mute (Table 2).

The mutism lasted $\sim 1$ year. Fifteen months after the accident, he was wheelchair-bound. He was cooperative and communicative. He understood verbal requests, but exhibited marked mental slowness. His severe dysarthria was characterized by slow speech rate and breathiness to such a degree that he stopped speaking after 5 min of conversation. Grammatical form of his utterances and word finding were unimpaired.

Case 2. In the acute phase, a 5-year-old girl was injured in a car accident. On admission to the intensive care unit, she was comatose (GCS: E1M5V1). CT scan demonstrated fractures of the left parietal and temporal bones, multiple areas of contusion in the left hemisphere, obliterated basal cisterns, and shift of the midline structures toward the right side. Intracranial pressure in the first hours was increased to $50-60 \mathrm{~mm}$ $\mathrm{Hg}$, and she was intubated and artificially hyperventilated. Neurologic examination revealed a right flaccid hemiparesis, including a right central facial nerve paresis and a bilateral abducens nerve paralysis. Sixteen days after onset, she was extubated. She became more responsive to her environment: She reached for objects and waved goodbye. She did not speak, but phonated in emotional context.

In the next 6 weeks, her mobility improved rapidly. A therapy session was videotaped 6 months after the accident (Table 2).
From the *Department of Neurology; University Hospital

Rotterdam-Dijkzigt; Rotterdam; and ${ }^{\top}$ Department of Medical

Psychology; Ziekenhuis Walcheren; Vlissingen, The Netherlands.
Communications should be addressed to:

Dr. van Mourik; Department of Medical Psychology; Ziekenhuis Walcheren; Postbus 3200; 4380 DD Vlissingen, The Netherlands. Received January 11, 1995; accepted June 19, 1996. 
Table 1. Illustrative case studies of acquired neurologic childhood mutism

\begin{tabular}{lll}
\hline \hline Reference & \multicolumn{1}{c}{ Localization } & \multicolumn{1}{c}{ Etiology } \\
{$[2]$} & Left cerebral hemisphere & Traumatic \\
{$[3]$} & Left cerebral hemisphere & Vascular \\
{$[4]$} & Left cerebral hemisphere & Traumatic \\
{$[5]$} & Left cerebral hemisphere & Traumatic \\
{$[6]$} & Right cerebral hemisphere & Vascular \\
{$[7]$} & Perisylvian areas & Epileptic \\
{$[8]$} & Perisylvian areas & Epileptic \\
{$[9]$} & Opercula & Infectious \\
{$[10]$} & Opercula & Epileptic \\
{$[11]$} & Opercula & Vascular \\
{$[2]$} & Diffuse & Traumatic \\
{$[12]$} & Cortical/subcortical pathology & Infectious \\
{$[13]$} & Thalamus & Traumatic \\
{$[14]$} & Third ventricle & Tumor \\
{$[15]$} & Basal ganglia & Infectious \\
{$[16]$} & Brainstem & Tumor surgery \\
{$[17]$} & Brainstem & Tumor \\
{$[18-21]$} & Cerebellum & Tumor surgery \\
& & \\
\hline & & \\
\hline & &
\end{tabular}

Fourteen months after the trauma, she produced the first word"Mama" - but with articulatory problems. Three years after the accident, she is still severely aphasic: Language comprehension is severely impaired, and her verbal output shows articulatory problems and loss of syntax.

Case 3. The medical history of Case 3 is complex; He had been examined at the age of 3 years for delay in motor development. Neurologic examination revealed slight ataxia of all extremities. CT scan did not demonstrate cerebellar pathology or other abnormalities, and the etiology remained unknown. Despite his delayed motor development, his speech and language developed normally. At the age of 5 years, he fell from his tricycle and was admitted to the hospital with brain concussion, from which he recovered with no additional deficit. His school performance was age-appropriate.

In the acute phase, at the age of 9 years, he fell again from his bicycle and complained of dizziness and blurred vision. In the next hours, consciousness deteriorated. Neurologic examination disclosed a restless, confusional state (GCS: E3M4V3). There were no signs of meningeal irritation or increased intracranial pressure. Pupils were of equal size and reacted to light. One day after hospital admission, he was still restless; he groaned to painful stimuli and uttered only a few words. There were bilateral Babinski responses. CT scan demonstrated narrow ventricles but no focal abnormalities. The course was complicated by increased body temperature. A second CT scan and cerebrospinal fluid were normal. His verbal output deteriorated in $\leqslant 1$ day: He vocalized unrecognizable sounds (GCS: E3M3V2), after which he became completely mute.

One month after the trauma occurred, we analyzed his behavioral features (Table 2). Neuropsychologic examination initially revealed a neglect for all verbal and nonverbal auditory stimuli: cortical deafness. He did not startle to sounds and behaved as though he were totally deaf. He did not appear to be concerned about his inability to hear. Ear, nose and throat examination and brainstem auditory evoked potentials were normal.

Five weeks after the trauma occurred, he became aware of spoken language and sounds but was unable to recognize their meaning: auditory agnosia. However, he was able to write the names of visually presented objects. Two weeks later, he would correctly identify $50 \%$ of auditorily presented sounds, such as musical instruments. He still demonstrated auditory language problems (verbal auditory agnosia) to such a degree that he could not point to objects for which the names were presented auditorily, whereas he responded adequately to written words. Eleven weeks after the trauma, his language comprehension had returned to normal. Moreover, his language production had gradually improved. He spoke with a whispering voice and was able to repeat long sentences. He had slight word-finding difficulties.

One year after the accident, he had regained his premorbid level of functioning except for mild word-finding difficulties. Five years after this episode, he has no language problems and his school performance is at age-appropriate level.

Case 4. A 5-year-old boy was admitted with early morning vomiting, diplopia, and staggering gait. Neurologic examination demonstrated bilateral papilledema, a vertical skew deviation, and a slight ataxia of the left arm and leg. CT and MRI scans revealed a tumor of the cerebellar vermis, with some small calcifications and cystic components filling the fourth ventricle, and associated hydrocephalus. A ventriculoperitoneal shunt was inserted. In a second surgical session, a medulloblastoma was completely removed macroscopically. Postoperatively, he had severe ataxia of trunk and limbs and was extremely apathetic. He spoke only a few words for 2 days, after which he became mute.

The mutism lasted 5 weeks. Emotional phonation (crying, whining, laughing) was intact throughout the mute phase. Coordination of movements during eating and swallowing were intact. He could lick his lips while eating, but voluntary orofacial movements could not be initiated on request despite intact language comprehension. Later, simple orofacial movements, such as eye closure, tongue protrusion, and lateral tongue movements, were performed adequately. Complex learned voluntary movements such as whistling, blowing, imitating an angry face, and blowing a kiss could be performed adequately soon before the mutism disappeared. Subsequently, he was dysarthric: He spoke single words with slow speech rate and a strained strangled voice. Three months postoperatively, his spontaneous speech was limited, but he was able to repeat sentences slowly. Four months after the tumor resection, speech was normal except for a slightly slow rate. (Further details are reported by Van Dongen et al. [Case C4] [21].)

\section{Results}

In accordance with the original description by Cairns [14] and later studies [12,13,22], Case 1 is a typical example of akinetic mutism: The patient is immobile, completely silent, and nonresponsive. Therefore, the mutism in this context is nonselective and part of a global lack of responsiveness. In this clinical context, the associated cognitive and behavioral features cannot be assessed as was possible in the other cases. In Case 1, the probable speech disorder associated with the mutism was anarthria since severe dysarthria followed the mute phase. Aphasia could not be excluded but was unlikely since the boy did not manifest impairments of language comprehension after the mute phase.

In Case 2, it was evident that the mutism was an initial phase of severe aphasia, since evaluation during the mute phase demonstrated severe impairment of language comprehension. The patient was eager to communicate, but had limited ability to convey information by alternative means such as gestures. This severe aphasia has influenced the long duration of the mutism. Three years after the onset of mutism, the girl is still severely aphasic.

Mutism has a high prevalence in childhood aphasia $[3,4]$ in which disorders of language comprehension are common [23]. Case 2 shows remarkable resemblance to the case described by Jordan [24] with incomplete recovery over a protracted period after the "return from silence." 
Table 2. Behavioral features during the mute phase of ANCM

\begin{tabular}{|c|c|c|c|c|c|}
\hline & & Case 1 & Case 2 & Case 3 & Case 4 \\
\hline Feature & $\begin{array}{l}\text { Age of Onset (yrs) } \\
\text { Time Post Onset }\end{array}$ & $\begin{array}{c}11 \\
4 \mathrm{mo}\end{array}$ & $\begin{array}{l}5 \\
6 \mathrm{mo}\end{array}$ & $\begin{array}{c}9 \\
1 \mathrm{mo}\end{array}$ & $\stackrel{5}{2 \text { wks }}$ \\
\hline Alertness & & "Wakeful", & $\begin{array}{l}\text { Attentive and } \\
\text { cooperative when } \\
\text { tested }\end{array}$ & $\begin{array}{l}\text { Attention could be } \\
\text { drawn only by } \\
\text { touching and } \\
\text { stimulating }\end{array}$ & $\begin{array}{l}\text { Attentive and alert to } \\
\text { daily activities and } \\
\text { when tested }\end{array}$ \\
\hline Motor behavior & & $\begin{array}{l}\text { Tetraplegia left > } \\
\text { right; } \\
\text { "motionless" } \\
\text { except for slow } \\
\text { eye movements } \\
\text { and head turning } \\
\text { when addressed }\end{array}$ & $\begin{array}{l}\text { Right-sided central } \\
\text { facial nerve paresis } \\
\text { and hemiplegia }\end{array}$ & $\begin{array}{l}\text { No abnormalities } \\
\text { except for } \\
\text { previously existing } \\
\text { ataxia }\end{array}$ & $\begin{array}{l}\text { Severe truncal and } \\
\text { limb ataxia }\end{array}$ \\
\hline $\begin{array}{l}\text { Orofacial } \\
\text { movements }\end{array}$ & & $\begin{array}{l}\text { Orofacial movements } \\
\text { could not be } \\
\text { elicited; drinks and } \\
\text { swallows with } \\
\text { help; smacks his } \\
\text { lips; no facial } \\
\text { expression }\end{array}$ & $\begin{array}{l}\text { Normal chewing, } \\
\text { swallowing; simple } \\
\text { and complex oral } \\
\text { movements } \\
\text { impaired; vivid } \\
\text { emotional } \\
\text { expression; } \\
\text { incidentally } \\
\text { unphonated } \\
\text { articulatory } \\
\text { movements }\end{array}$ & $\begin{array}{l}\text { Normal chewing, } \\
\text { drinking, and } \\
\text { swallowing; little } \\
\text { facial expression }\end{array}$ & $\begin{array}{l}\text { Eats and drinks } \\
\text { greedily; simple } \\
\text { orofacial } \\
\text { movements } \\
\text { possible; complex } \\
\text { learned movements } \\
\text { impossible; vivid } \\
\text { emotional } \\
\text { expression }\end{array}$ \\
\hline Phonation & & Completely silent & $\begin{array}{l}\text { Emotional } \\
\text { vocalization: } \\
\text { giggling, growling }\end{array}$ & Completely silent & $\begin{array}{l}\text { Whining and loud } \\
\text { sobs; normally } \\
\text { phonated laughing }\end{array}$ \\
\hline Communication & & $\begin{array}{l}\text { "Promise of speech" } \\
{[14]}\end{array}$ & $\begin{array}{l}\text { Good eye contact; } \\
\text { nodding assent, } \\
\text { shaking head; } \\
\text { contextually } \\
\text { adequate gestures }\end{array}$ & $\begin{array}{l}\text { Reacts cooperatively } \\
\text { upon gestures; no } \\
\text { initiative to } \\
\text { communication }\end{array}$ & Attentive listener \\
\hline Language & & $\begin{array}{l}\text { Absent for all } \\
\text { modalities }\end{array}$ & $\begin{array}{l}\text { Understands simple } \\
\text { commands in } \\
\text { context }\end{array}$ & $\begin{array}{l}\text { Neglect of } \\
\text { (repetitive) verbal } \\
\text { and nonverbal } \\
\text { auditory stimuli }\end{array}$ & $\begin{array}{l}\text { Good language } \\
\text { comprehension }\end{array}$ \\
\hline Mental activity & & "Mindless"' [14] & $\begin{array}{l}\text { Limited attention } \\
\text { span: concentrated } \\
\text { for } 30 \text { min; } \\
\text { bradyphrenous; } \\
\text { sorting of three } \\
\text { forms by trial and } \\
\text { error; nonverbal IQ } \\
\text { at 4-year level }\end{array}$ & $\begin{array}{l}\text { Aloof; no purposeful } \\
\text { actions }\end{array}$ & $\begin{array}{l}\text { Good performance at } \\
\text { complex form } \\
\text { sorting task; } \\
\text { anticipatory and } \\
\text { cooperative when } \\
\text { tested }\end{array}$ \\
\hline Emotions & & "Mindless"' [14] & $\begin{array}{l}\text { Cheerful most of the } \\
\text { time; strong } \\
\text { emotional reactions } \\
\text { in response to } \\
\text { environmental } \\
\text { changes; impulsive }\end{array}$ & $\begin{array}{l}\text { No sign of emotional } \\
\text { awareness }\end{array}$ & $\begin{array}{l}\text { Contextually } \\
\text { adequate } \\
\text { expression of } \\
\text { internal state such } \\
\text { as frustration, pain, } \\
\text { pleasure }\end{array}$ \\
\hline
\end{tabular}

In Case 3, the mutism occurred in the context of a severe cortical deafness, apparent unawareness of auditory stimuli in the absence of peripheral or brainstem damage [25]. Subsequently, he manifested auditory agnosia: He was aware of auditory input but unable to recognize its meaning. Speech returned when he became able to understand nonverbal sounds and language comprehension improved. After 1 year, he exhibited only mild word-finding problems.

Case 4 presented with a rather pure mutism after resection of a cerebellar tumor: During the mute phase, he was able to phonate, he understood language at age-appropriate level, as was demonstrated by adequate performances on receptive language tasks, and he performed well on nonverbal cognitive tasks. However, initiation of voluntary complex movements was significantly impaired. The onset of dysarthric speech coincided with the recovery of voluntary complex orofacial movements. Therefore, we hypothesize that the mutism was due to a loss of the ability to initiate and coordinate complex orofacial movements. Such a clinical picture resembles other cases with mutism due to posterior fossa surgery [18-21].

The most relevant data of the four cases are summarized in Table 3. 


\begin{tabular}{lcccc}
\hline \hline \multicolumn{1}{c}{ Parameter } & $\begin{array}{c}\text { Case 1, } \\
\text { Akinetic Mutism }\end{array}$ & $\begin{array}{c}\text { Case 2, } \\
\text { Aphasic Mutism }\end{array}$ & $\begin{array}{c}\text { Case 3, } \\
\text { Cortical } \\
\text { Deafness }\end{array}$ & $\begin{array}{c}\text { Case 4, } \\
\text { Posterior } \\
\text { Fossa Mutism }\end{array}$ \\
$\begin{array}{lccc}\text { Alertness } \\
\text { Cranial nerves }\end{array}$ & - & + & + & + \\
Orofacial movements & + & Right-sided VII, & + & + \\
Phonation & bilateral VI & & + \\
Communicative intent & - & + & - & + \\
Language comprehension & - & + & - & + \\
Symbols: $+=$ Intact; $\pm=$ Moderately impaired; - & $=$ Severely impaired; ? $=$ Could not be \\
assessed. & & & & \\
\hline
\end{tabular}

\section{Discussion}

ANCM is a complex phenomenon occurring in neurologic disease in childhood. The underlying mechanisms are various, resulting from damage anywhere between the cerebral cortex and the peripheral speech apparatus. The pediatric literature on ANCM consists of case studies describing the occurrence of mutism and presenting occasional definitions in a specific clinical context. Our cases were examined and are presented in a standard fashion to illustrate the many faces of ANCM and to distinguish various forms of mutism as a manifestation of distinct underlying mechanisms. On the basis of our analyses and other studies, we discriminate between the following causes: deficient initiation of cognition and speech, auditory agnosia and aphasia, and dysarthria.

Deficient Initiation of Cognition and Speech. Akinetic mutism (AM) is probably the type of mutism best known to clinicians. It is a neurobehavioral condition characterized by deficient initiation or activation of behavior and cognition. Case 1 fits the criteria for AM, which are distinct from those of the vegetative state (VS) [22]. Case 1 followed requests to suck and swallow, whereas in VS behavior responses consist of reflexes only. Visual tracking, crucial to the diagnosis of AM, is more sustained in AM than in VS, in which visual tracking, if present, extinguishes rapidly. In addition, in AM the facial expression shows "promise of speech" which is absent in VS, in which signs of communication with the environment are absent [22]. In most cases of AM, a minimal degree of movement and/or speech can be elicited depending on the nature and intensity of stimulation provided [22]. We could elicit no emotional phonation or speech in Case 1.

Auditory Agnosia and Aphasia. Case 3 manifested cortical deafness resolving into auditory agnosia, which suggests that in this child the loss of meaningful auditory input precluded verbal output. This is in contrast to conditions in adults with cortical deafness, who retain the ability to produce speech [25].

Mutism has a high prevalence in acquired childhood aphasia (ACA) $[3,4]$. It may be related to a language comprehension disorder as in Case 2. After the 14 month mute phase, her verbal output was severely aphasic and language comprehension was impaired. In contrast to earlier notions, a more recent description of ACA states that impaired auditory comprehension is detected in almost all aphasic children if appropriate tests are administered and may range from mild difficulties to total loss of receptive communication [23].

In acquired aphasia with seizure disorders LandauKleffner syndrome, the severe disruption of language comprehension (verbal auditory agnosia) may also result in loss of verbal output (mutism) [26]. This clinical picture has been described only in children. In adults, "aphasic" mutism usually is transient, even in types of aphasia in which language comprehension is severely impaired [27]. However, mutism is not necessarily linked to language comprehension disorder. It may also be the manifestation of a severe articulation deficit with relatively preserved language comprehension, as may be the case in Broca's aphasia or verbal apraxia [5].

Mutism as an initial stage in ACA may be related to frontorolandic lesions [4] or subcortical lesions [3]. Furthermore, a language comprehension disorder may be a greater risk factor in childhood than in adulthood for mutism of long duration.

Dysarthria. Interference with any of the basic motor processes involved in speech production results in dysarthria. Anarthria, mutism of dysarthric nature, is the most severe manifestation. Damage affecting motor subsystems may affect motor aspects of speech in various ways.

Bilateral damage to the anterior opercular region of the primary motor cortex causes loss of volitional control of muscles innervating lips, jaw, tongue, velum, and pharynx rendering the patient mute with constant drooling. In contrast, involuntary movements (yawning and laughing) are preserved [9]. Patients are alert and have normal language comprehension. Mutism may be the main neurologic sequela after structural damage to the anterior opercula. In contrast, in the opercular syndrome of epileptic origin, discharges in the opercular region cause only brief episodes of speech arrest $[7,8]$.

Mutism may also occur in the context of an akinetic- 
rigid syndrome, as described by Pranzatelli et al. [15], who reported 6 children with acquired parkinsonism in whom mutism was associated with drooling and dysphagia in the context of such a syndrome. After appropriate medication, the mutism resolved into dysarthric speech.

Mutism after resection of a posterior fossa tumor has received much attention in the literature. After an initially uneventful recovery from the operation, children cease to speak. The children are alert and perform in age-adequate manner on nonlanguage tasks; their language comprehension is adequate [18-21]. The mute phase is of variable duration and is followed by severe dysarthria with good recovery. With respect to the pathophysiological mechanism, we previously observed [21] that in addition to the surgical lesion of cerebellar structures ventricular localization of the tumor, adherence to the dorsal brainstem, and hydrocephalus at presentation were necessary risk factors. The motor impairment underlying the loss of speech is unknown. Observations in our patients (Case 4) suggest that mutism may be associated with the inability to initiate voluntary complex orofacial movements.

Frim and Ogilvy [16] reported mutism with subsequent cerebellar dysarthria after the surgical resection of a cavernous malformation of the right pons at the level of the middle cerebellar peduncle. Brainstem lesions may also produce the locked-in syndrome, in which state patients are alert, cognitively aware of their environment, and capable of communication but incapable of speech or movement. The hallmark signs are quadriplegia and aphonia, caused by lesions involving the ventral pons [22].

A further distinction in types of mutism was made by Cummings et al. [28] and Von Cramon [29], who distinguish between the loss of emotional vocalization and the loss of propositional speech. They provide evidence that the limbic system is involved in the phonatory expression of emotion such as laughing and crying, whereas descending neocortical systems subserve propositional speech and volitional facial movements. Von Cramon [29] followed adult patients with traumatic brain injuries during the mute phase and reported that "complete" mutism was followed by a phase of nonverbal emotional vocalization (verbal mutism), signaling the recovery of midbrain function. In our cases, we could distinguish between complete mutism (Cases 1 and 3) and loss of propositional speech with preserved phonation in laughing, whining, and crying (verbal mutism) (Cases 2 and 4). These observations may add to the clarification of the neuropathological mechanisms underlying mutism.

By standard examination of 4 mute children, we have illustrated that mutism is associated with various neurobehavioral features. Our study may be considered an attempt to map the heterogeneity of ANCM and its underlying mechanisms. Detailed neuropsychological analysis as proposed in Appendix 1, is pertinent since the lack of speech itself provides no indication of the underlying mechanism. This analysis contributes to early statements as to the evolution of the speech/language problem and the expected long term disability.

\section{Appendix 1}

Protocol for the evaluation of mute children

1. Cranial nerves (lower)

Drinking, chewing, swallowing, coughing

2. Involuntary facial movements

Observation of laughing, yawning, facial expression

3. Simple orofacial movements

Eye closure, tongue protrusion, lateral tongue movements, licking of the lips, lateral jaw movements, showing teeth

4. Complex orofacial movements

Whistling, blowing, clicking of the tongue, showing an angry face, pretending to sense a nasty smell, blowing a kiss

5. Phonation

Absence or presence of phonation, emotional voiced utterances such as crying, whining, laughing, isolated voiced sounds

6. Auditory input

Localization and identification of nonverbal sounds such as environmental noise, animal sounds, musical instruments

7. Language comprehension

Simple commands (close your eyes), complex commands, language comprehension tests (Peabody Picture Vocabulary Test, Test for Reception of Grammar (TROG), reading text)

8. Alternative means of communication Shaking, nodding, gesturing, writing

9. Nonverbal tasks Making puzzles, sorting tasks, nonverbal intelligence tasks

\section{References}

[1] Lebrun Y. Prologue. In: Mutism. London: Whurr Publishers, 1990:1.

[2] Levin HS, Madison CF, Bailey CB, Meyers CA, Eisenberg HM, Guinto FC. Mutism after closed head injury. Arch Neurol 1983;40:601-6.

[3] Martins IP, Ferro JM. Acquired childhood aphasia: a clinicoradiological study of 11 stroke patients. Aphasiology 1993;7:489-95.

[4] Hecaen H. Acquired aphasia in children: revisited. Neuropsychologia 1983;21:581-7.

[5] Square PA, Aronson AE, Hyman E. Case study of the redevelopment of motor speech control following acquired brain damage in early childhood. Am J Speech Lang Pathol 1994;3:67-80.

[6] Burd L, Gascon G, Swenson R, Hankey R. Crossed aphasia in early childhood. Dev Med Child Neurol 1990;32:539-46.

[7] Deonna TW, Roulet E, Fontan D, Marcoz JP. Speech and oromotor deficits of epileptic origin in benign epilepsy of childhood with rolandic spikes (BPERS). Relationship to the acquired aphasia-epilepsy syndrome. Neuropediatrics 1993;24:83-7.

[8] Shafrir Y, Prensky AL. Acquired epileptic opercular syndrome: a second case report, review of the literature, and comparison to the Landau Kleffner syndrome. Epilepsia 1995;36:1050-7.

[9] Prats JM, Garaizer C, Uterga JM, Urroz MJ. Operculum syndrome in childhood: a rare cause of persistent speech disturbance. Dev Med Child Neurol 1992;34:359-64.

[10] Colamaria M, Sgrò V, Caraballo R, et al. Status epilepticus in benign rolandic epilepsy manifesting as anterior opercular syndrome. Epilepsia 1991;32:329-34.

[11] Groswasser Z, Groswasser-Reider I, Korn C. Biopercular lesions and acquired mutism in a young patient. Brain Inj 1991;5:331-4.

[12] Echiverri HC, Tatum WO, Merens T, Coker SB. Akinetic mutism: pharmacologic probe of the dopaminergic mesencephalofrontal activating system. Pediatr Neurol 1988;4:228-30. 
[13] Shinoda M, Tsugu A, Oda S, et al. Development of akinetic mutism and hyperphagia after left thalamic and right hypothalamic lesions. Childs Nerv Syst 1993;9:243-5.

[14] Cairns H, Oldfield RC, Pennybacker JB, Whitteridge D. Akinetic mutism with an epidermoid cyst of the 3rd ventricle. Brain 1941; 64:273-90.

[15] Pranzatelli MR, Mott SH, Pavlakis SG, Conry JA, Tate ED. Clinical spectrum of secondary Parkinsonism in childhood: a reversible disorder. Pediatr Neurol 1994;10:131-40.

[16] Frim DM, Ogilvy CS. Mutism and cerebellar dysarthria after brainstem surgery: case report. Neurosurgery 1995;36:854-7.

[17] Masazuwa H, Sato J, Kamitani H, Kamikura T, Aoki N. Pontine gliomas causing locked-in syndrome. Childs Nerv Syst 1993;9:256-9.

[18] Rekate HL, Grubb RL, Aram DM, Hahn JF, Ratcheson RA. Muteness of cerebellar origin. Arch Neurol 1985;42:697-8.

[19] Ammirati M, Mirzai S, Samii M. Transient mutism following removal of a cerebellar tumor. Childs Nerv Syst 1989;5:12-4.

[20] Ferrante L, Mastronardi L, Acqui M, Fortuna A. Mutism after posterior fossa surgery. J Neurosurg 1990;72:959-63.

[21] Van Dongen HR, Catsman-Berrevoets CE, Van Mourik M. The syndrome of 'cerebellar' mutism and subsequent dysarthria. Neurology 1994;44:2040-6.
[22] Recommendations for use of uniform nomenclature pertinent to patients with severe alterations of consciousness. Arch Phys Med Rehabil 1995;76:205-9.

[23] Paquier PF, van Dongen HR. Review of research on the clinical presentation of acquired childhood aphasia. Acta Neurol Scand 1996;93: $428-36$.

[24] Jordan FM. Whatever happened after the 'return from silence'? Brain Inj 1994;8:277-83.

[25] Mendez MF, Geehan GR. Cortical auditory disorders: clinical and psychoacoustic features. J Neurol Neurosurg Psychiatry 1988;51: $1-9$.

[26] Paquier P, van Dongen HR, Loonen MCB. The Landau Kleffner syndrome or 'acquired aphasia with convulsive disorder': long-term follow-up of six children and a review of the recent literature. Arch Neurol 1992;49:354-9.

[27] Ziegler W, Ackermann H. Mutismus und Aphasie--eine Literaturübersicht. Fortschr Neurol Psychiatr 1994;62:366-71.

[28] Cummings JL, Benson F, Houlihan JP, Gosenfeld LF. Mutism: loss of neocortical and limbic vocalization. J Nerv Ment Dis 1983;171: 255-9.

[29] Von Cramon D. Traumatic mutism and the subsequent reorganization of speech functions. Neuropsychologia 1981:19:801-5. 